Bond University

Research Repository

\title{
Cognitive failures at work, mindfulness, and the Big Five
}

Klockner, Karen D; Hicks, Richard E.

Published in:

Global Science and Technology Forum (GSTF) Journal of Psychology

DOI:

10.5176/2345-7872_2.1_22

Licence:

CC BY-NC

Link to output in Bond University research repository.

Recommended citation(APA):

Klockner, K. D., \& Hicks, R. E. (2015). Cognitive failures at work, mindfulness, and the Big Five. Global Science and Technology Forum (GSTF) Journal of Psychology, 2(1), 1-7. https://doi.org/10.5176/2345-7872_2.1_22

\section{General rights}

Copyright and moral rights for the publications made accessible in the public portal are retained by the authors and/or other copyright owners and it is a condition of accessing publications that users recognise and abide by the legal requirements associated with these rights.

For more information, or if you believe that this document breaches copyright, please contact the Bond University research repository coordinator. 


\title{
Cognitive Failures at Work, Mindfulness, and the Big Five
}

\author{
Karen Klockner and Richard E. Hicks
}

\begin{abstract}
Cognitive failures at work (or errors in the workplace including blunders and memory lapses), can lead to considerable personal and organisational damage, even damage well beyond national borders in some organisations. Workplace errors may have a personality base; and mindfulness (or mindlessness) also appears to be related to workplace errors generally. Given the importance and cost of errors in the workplace it is of concern that no previous research appears to have addressed the relationships between cognitive failures at work, personality and mindfulness together. We aimed to address this gap. We administered the Cognitive Failures Questionnaire, the Mindful Attention Awareness Scale (MAAS) and the Big Five International Personality Item Pool 50-item questionnaire (IPIP) to a sample of 92 Australian-based employees from a variety of organisations. Our results showed workplace errors (including lapses in general memory, blunders, distractions and recall of names) were related to lower levels of mindfulness and to lower levels of emotional stability (that is, the other end of the neuroticism- emotional stability continuum). Extraversion was associated with not making blunders, but the other three factors of the Big Five (Openness, Agreeableness, Conscientiousness) were not found to be related to workplace errors. These results demonstrate important relationships between mindfulness and workplace errors; and personality (mainly Neuroticism- Emotional Stability) and workplace errors. Giving special attention to mindfulness training and to effective mental health training in organisations is recommended, especially where lapses in attention or workplace actions can lead to costly personal and organisational mistakes.
\end{abstract}

Keywords- Cognitive failures; workplace errors; mindfulness; the Big Five, personality; workplace blunders

\section{INTRODUCTION}

Cognitive failures or errors in the workplace include distractions, blunders, memory lapses and oversights and are common and can have from minor to disastrous consequences. Examples of errors include: sending an email to "all" instead of one selected person; adding funds incorrectly and not checking, momentarily being distracted in walking or driving leading to accidents at home, office or on the highway; not checking air pressures or fuel gauges; or not checking where tools are and what has happened to them (including in surgery); not contacting an individual in due time .... the list is endless- some consequences clearly more disastrous and costly than others. Such cognitive-based mistakes on simple tasks that a person should normally be able to complete without error have been termed cognitive failures [1].

Cognitive failures have been related to an inability to attend to a task and to lapses of attention [2, 3], to errors in task execution (blunders) and to personality traits such as boredom proneness [4], and to overload of short-term memory leading (for example) to accidents and errors [5].

\section{A. Cognitive Failures and Mindfulness}

Cognitive failures and relatively error-free safe work behaviours have been linked with attentiveness at work Mindfulness is associated directly with awareness. Therefore, it would be anticipated that there would be overlap between cognitive failures and (lack of) mindfulness. But as Dane and Brummel [6] have indicated this year (2014), few studies exist to date on the relationships between mindfulness and cognitive failures in the workplace context.

Mindfulness is commonly defined as "the state of being attentive to and aware of what is taking place in the present $\ldots$ and can be considered an enhanced attention to and awareness of current experience or present reality" [7, p. 822]. Mindfulness is said to include a sense of self as observer, where the self hears more clearly and notices distinctly without distortion what is happening in the present moment, seeing, hearing and feeling the experience without judgment or thought. It is a sense of 'self' as the observer in the moment rather than of an 'I' who is doing and planning things. The practice of mindfulness enables one to "inhabit the vantage point of the observer" [8, p. 310].

Mindfulness started within traditional Buddhism emphasising mindful meditation and related skills, according to Kabat-Zinn [9]; a more 'western' interpretation with attention directed to cognitive processes was developed and emphasised by Langer [10]. Considerable interest has been shown in mindfulness by western society since the year 2000 with emphasis on cognitive processes involved. This interest is shown for example in the dedication of special issues of journals to mindfulness (cf., the Journal of Social Issues, 2000; Emotions February, 2010; and the Journal Mindfulness 
itself, newly operating from 2010) and in the now many different applications including, beyond the early origins in meditation, to areas such as clinical and health psychology $[11,12,13]$; sporting achievement [14] and business and the workplace (e.g., in distress, resilience, and well-being at work: [15]); and in accidents and work safety [2, 16, 17].

Ellen J. Langer is recognised as one of the earliest contributors in the study of mindfulness in a western context following her work on mindlessness $[10,18]$. Much work is still done examining elements from the eastern tradition [19, $20,21,22,23,24,25,26]$ but Langer's work underpins much of our western studies. Langer was keen to see how individuals could become more mindful by developing skills around attention and awareness.

A major value from mindfulness studies is that mindfulness is seen to be a state-based rather than a traitbased characteristic, that is, that mindfulness can be developed in individuals. Many training programs now run in organisations and professional settings on the premise that personal and work performance is enhanced by such training $[12,27,28,29]$.

Despite the above studies, there has been little research that examines mindfulness and cognitive errors directly. Therefore, the current study aimed to address this gap. Based on the information on mindfulness and cognitive failures from research, it was anticipated that there would be a strong (negative) correlation between mindfulness and cognitive errors or failures.

It was also decided to examine further the relationships of cognitive error propensity to personality factors. Studies on cognitive failures and personality are now reviewed; followed by studies linking mindfulness and personality. Hypotheses about the relationships are then raised and subsequently the study and its results are presented.

\section{B. Cognitive Failures and Personality}

Personality variables have been implicated in cognitive failures (for example, in boredom proneness: [4]; and in unstable emotional patterns, neuroticism and extraversion:[30]). The current predominant model of personality factors is the Big-Five factor model, composed of five factors: Neuroticism, Extraversion, Openness to Experience, Agreeableness and Conscientiousness [31]. It would be useful to know how cognitive failures and the Big Five factors are related in a workplace context. While there is considerable debate on whether five factors best describes the correct number of personality dimensions and whether sub-factors should be examined also, this model provides a good basis for initial studies of the links between cognitive failures and a set of broad personality characteristics. A description of each of the five factors follows, along with reference to relevant research and a potential hypothesis in regard to the factor.

Neuroticism. Neuroticism (N) refers to the lower end of emotional stability and is associated with being emotional, temperamental and anxious [32]. Neuroticism has been found to be a significant predictor of occupational accidents and one researcher (Robertson [33]) conceded that people with high scores on $\mathrm{N}$ had greater reactivity to environmental stressors and would be more distractible from ongoing tasks. Other authors (including [34)] have identified that being dispositionally insecure, negative and anxious, influenced goal striving processes by promoting a failure orientation and disrupting concentration on work tasks. Accordingly for our study, it was expected and hypothesised that $\mathrm{N}$ would be highly correlated with cognitive failures at work.

Extraversion. Extraversion refers to the degree to which an individual actively engages in the social environment, with extraverted individuals being described as outgoing, sociable and adventurous [32]. Previous research has shown that individuals who are extraverted seem to be better adjusted (that is, score lower on neuroticism) [35]. It could be hypothesised that this personality trait of Extraversion would be associated with fewer cognitive errors though the adventurous side of extraversion suggests a confounding aspect that would contribute to cognitive errors. Nevertheless, research in 2006 with Italian secondary school students [30] suggested that extraversion was significantly and negatively correlated with perceived cognitive failures in this young age group; it was anticipated therefore that extraversion would be related negatively to cognitive errors in our workplace sample.

Openness to Experience. Individuals open to experience are characterised as being imaginative, seeking variety and being intellectual. Openness to experience refers to the degree to which an individual accepts new or unconventional thoughts, experiences being imaginative, shows curiosity and demonstrates foresight [32]. Low levels of openness to experience are associated with a preference for familiarity, simplicity and closure with a tendency to be less adventurous, and more socially conforming and conventional [36]. According to one study [30], high openness to experience was associated with low propensity for cognitive failures. Openness to experience could indeed be associated with fewer cognitive errors (highlighting the nonadventurous side of low levels of openness) though again a mix of other aspects such as curiosity, exploration, and acceptance of new ideas or methods as part of openness could contribute in some instances to errors. These aspects suggest a confounding aspect that could limit the relationship between cognitive failures and openness. It could be hypothesised that this personality trait of Openness to Experience would be unlikely to be associated with cognitive failures. Based on this thinking we hypothesised that there would be either a negative link or no link between openness and cognitive errors.

Agreeableness. Individuals who score high on agreeableness tend to care for others, be good natured and possess modesty and trust. Low agreeableness may be considered a valid predictor of work accidents which could be transferable across occupational settings [37]. Low agreeableness has been found to be a predictor of deviant behaviours at work (including in disciplinary problems, organizational rule breaking and substance abuse) [38]. It was therefore hypothesised that this personality trait of agreeableness would be negatively associated with cognitive 
errors in our workplace sample.

Conscientiousness. Conscientious people are characterised as self-disciplined, emotionally stable, hardworking, and achievement-oriented [36]. Conscientious individuals follow social norms and engage in goal-directed behaviour, being responsible and organized [32], and tending to avoid risk-taking [39]. It was hypothesised that this personality trait would be negatively associated with cognitive errors in the workplace.

\section{Mindfulness and Personality}

The studies above have identified links between cognitive failures and mindfulness, and cognitive failures and personality. However, the third element in the set of comparisons needs to be examined: personality factors also appear related to mindfulness. For example, trait and attachment anxiety (or neuroticism) have been found to be negatively related to mindfulness [40]; and attention control, focusing attention, and avoiding distractions were positively related to mindfulness [41]. However, personality factors and their relationships to mindfulness need further study; as shown in several meta-analytic reviews, mainly of clinical studies [24, 42, 43] where conflicting results have been found. Giluk [42] in her meta-analysis studies, for example, found Neuroticism (negatively) and Conscientiousness both to be highly correlated with mindfulness; but in the case of each of Agreeableness, Extraversion and Openness to Experience, rather low correlations with mindfulness were found- significant in some studies, insignificant in others. It could be assumed that mindfulness and neuroticism would be negatively related also in our workplace sample but how the other four personality factors would relate to mindfulness is not clear.

No studies in a workplace context have been published linking cognitive errors or failures to mindfulness or to the Big Five personality factors, Recent conferences are addressing this area $[44,45,46]$ but further studies of the relationships are needed.

\section{Monitoring Issues: Cognitive Failures, Personality and Individual Mindfulness}

Conceptualising the main constructs (cognitive failures, mindfulness, personality) in such a way as to yield common agreement and common measuring instruments has had a varied history. However, the Cognitive Failures Questionnaire of Broadbent and colleagues (CFQ: [47]), seemed most useful for our study and had been used extensively in research. More details are given in Method.

There has also been special interest in striving to define and measure "mindfulness": as seen through the development of different measures of mindfulness with different subscales $[48,49]$. The development of several self report constructs to measure individual mindfulness has led to an expansion of knowledge and debate about what the mindfulness constructs are measuring and how many elements or facets are being measured [7, 48]. Some questionnaires are based on mindfulness as a singledimensional construct (as with the MAAS); others emphasise multiple domains, and at least seven such different measures have been developed [48]. Our study used the MAAS in an initial exploratory study of the relationships among mindfulness, personality, and cognitive failures.

To assess the Big Five we used the IPIP- International Personality Item Pool scales [50].

These questionnaires are discussed further in Method below.

\section{1) Hypotheses}

The purpose of this current study was thus to examine cognitive failures using the $\mathrm{CFQ}$ in relation to individual personality characteristics (using the IPIP), and in relation to mindfulness as assessed by the MAAS.

Hypothesis 1 predicted that scores on the Cognitive Failures Questionnaire (CFQ) would be negatively related to scores on mindfulness, as assessed using the MAAS.

Hypothesis 2 predicted that the CFQ scores would be directly related to IPIP scores on neuroticism and negatively related or not related to each of the other characteristics (extraversion, openness, agreeableness and conscientiousness) with extraversion and conscientiousness most likely to be related significantly.

Hypothesis 3 (with several sub-hypotheses regarding each factor) examined how mindfulness and personality attributes were related in this workplace sample, with hypotheses that suggested mindfulness would be significantly related to neuroticism (negatively) and less strongly to extraversion, conscientiousness, agreeableness, and openness to new experiences.

\section{METHOD}

\section{A. Participants}

The 92 participants in this study came from workplaces on the Gold Coast and northern New South Wales in Australia had agreed to participate in a larger study of mindfulness and its role in workplace safety- our study was a part of the larger study. Participants were predominantly tradespeople $(49 \%)$ with the balance being managers $(25 \%)$, professionals $(11 \%)$, clerks $(11 \%)$ and para-professionals (4\%). There were 58 males and 32 females, with ages ranging from 15 to $61+$ years with $28 \%$ reporting that they were between 41-50 years of age. All participants completed a package of questionnaires including the Mindful Attention Awareness Scale (MAAS), the IPIP measure of personality (IPIP), the Cognitive Failures Questionnaire (CFQ) and a bio-data questionnaire in which the participants indicated their gender, age bracket, type of employment, type of industry and occupational group. Two other questionnaires (on safety and satisfaction issues) were also used though these are not discussed in this paper. Two of the original 92 participants returned incomplete surveys and these were dropped from the analysis. 


\section{B. Measures}

\section{1) The Cognitive Failures Questionnaire}

The Cognitive Failures Questionnaire (CFQ: [47]) has 25 items and was developed to assess a person's likelihood of committing an error in the completion of everyday tasks. The CFQ measures the frequency of lapses in three areas: perception, memory, and motor function [51]. Validation studies [2, 17] have found strong relationships between lack of attentiveness and cognitive errors. The twenty-five items are each rated on a five-point Likert scale from 0 (Never) to 4 (Very often) and yield measures on four distinct factors or sub-scales (Memory, Distraction, Blunders and Names). An example item is "Do you daydream when you ought to be listening to something?"

Sound psychometrics exist for the total score and each of the four sub-scales of the Cognitive Failures Questionnaire with Cronbach's Alpha coefficients ranging from .76 to .86 for the sub-scales, and around .91 for the CFQ total score [51]. The current research also yielded similar coefficients, ranging from .68 to .84 for the four subscales to .89 for the total score.

\section{2) The Mindful Attention Awareness Scale (MAAS)}

The construct of Mindfulness was operationalised in dispositional terms by the Mindful Attention Awareness Scale (MAAS), a 15-item self-report instrument with a single factor of mindfulness. The scale has been validated with college students, working adults and cancer patient populations. A description of the scale and its validation can be found in [7] with the MAAS having been used now in many studies. The 15 items are each rated on a six-point Likert scale from 1 (almost always) to 6 (almost never). An example item is "It seems I am running on automatic without much awareness of what I'm doing".

Sound psychometrics have been found for the MAAS [7] with Cronbach Alpha coefficients ranging over several studies from 0.86 to 0.92 ; our own study yielded a Cronbach Alpha of .90.

\section{3) International Personality Item Pool (IPIP)}

A short form 50-item Big Five Personality measure from the International Personality Item Pool (IPIP) [50] was used as a measure of trait personality. The fifty items are each rated on a five-point Likert scale from 1 (Very inaccurate description) to 5 (Very accurate), and measure the Big-Five factors of extraversion, conscientiousness, agreeableness, openness to experience and neuroticism (10 items each scale). An example item is "I often forget to put things back in their proper place".

Sound psychometrics for the Big Five have been reported [50] including Cronbach's Alpha coefficients ranging from .74 to .88 for the five characteristics, with similar coefficients being reproduced in numerous other research projects using the IPIP. The current research also yielded similar coefficients, ranging from .65 to .87 for the five variables.

\section{RESULTS}

\section{A. The Hypotheses}

Hypothesis 1, that cognitive errors or failures as assessed by the CFQ, and mindfulness as assessed by the MAAS would be negatively correlated, was supported (see Table 1). The total scores on the CFQ (CFQTTOT) and the MAAS correlated -.73 , highly significantly and negatively. Significant correlations were evident across all four of the CFQ facets of cognitive failures, as well as in the total score itself.

Hypothesis 2 that CFQ and the IPIP Big Five would be correlated was partially supported. Table 1 also shows the correlation coefficients between of the four cognitive failures facets (and the total score) and each of the Big Five factors.

TABLE I. CORRELATIONS: COGNITIVE FAILURES WITH MiNDFULNESS AND THE BIG FIVE FACTORS $(\mathrm{N}=90)$

\begin{tabular}{|c|c|c|c|c|c|}
\hline & \multicolumn{5}{|c|}{ COGNITIVE FAILURES } \\
\hline & Memory & Distraction & Blunders & Names & CFTOT \\
\hline $\begin{array}{c}\text { Mindfulness } \\
\text { MAAS }\end{array}$ & $-.59 * *$ & $-.75^{* *}$ & $-.52^{* *}$ & $-.51^{* *}$ & $-.73^{* *}$ \\
\hline Personality- IPIP & & & & & \\
\hline Neuroticism & $.43^{* *}$ & $.44^{* *}$ & $.49^{* *}$ & $.35^{*}$ & $.52^{* *}$ \\
\hline Extraversion & -.15 & -.14 & $-.24 *$ & -.16 & -.19 \\
\hline Openness & -.05 & -.11 & -.04 & -.00 & -.04 \\
\hline Agreeableness & .16 & .02 & -.13 & -.06 & .00 \\
\hline Conscientiousness & -.01 & -.00 & -.00 & -.02 & -.00 \\
\hline & & & & & \\
\hline
\end{tabular}

Note. *,**Correlation is significant at the $0.05,0.01$ levels (2-tailed test); MAAS $=$ Mindful Attention Awareness Scale; CFTOT=Cognitive Failures Total

As predicted, the CFQ and Neuroticism scores were highly and significantly correlated both for the total $\mathrm{CF}$ scores and for each of its facets.

However, extraversion, predicted as being related negatively to cognitive failures, was not significantly related to the total CFQ score; nor were three of the four facets related to cognitive failures (only the category of Blunders was significantly related, and that weakly). Not one of the openness, agreeableness or conscientiousness factors was related significantly to total cognitive failures or its facets in this sample. These results are consistent with the hypothesis that there may be no link between openness and mindfulness; but not consistent with the hypotheses that agreeableness and conscientiousness would be negatively related to cognitive failures.

Hypothesis 3 outlined expected correlations between Mindfulness and the Big Five personality factor scores. Table 2 shows how the MAAS (Mindfulness) scores correlated with each of the Big Five factors. In support of the hypothesis that Neuroticism would be negatively related to mindfulness, a significant negative relationship was found ( $\mathrm{r}=-0.48^{* *}, \mathrm{p}<0.0005$, two tailed). Table 2 showed that not one of the other Big Five personality attributes was significantly related to mindfulness in our sample. 
TABLE II. CORRElations: Mindfulness AND THE BIG Five FACTORS $(\mathrm{N}=90)$

\begin{tabular}{|c|c|c|c|c|c|}
\hline & \multicolumn{5}{|c|}{$\begin{array}{c}\text { IPIP Personality factors } \\
\text { Neuroticism, Extraversion, Openness, Agreeableness, } \\
\text { Conscientiousness }\end{array}$} \\
\hline & $\mathbf{N}$ & $\mathbf{E}$ & $\mathbf{O}$ & $\mathbf{A}$ & $\mathrm{C}$ \\
\hline $\begin{array}{c}\text { Mindfulness } \\
\text { MAAS }\end{array}$ & $-.48 * *$ & .06 & .13 & -.11 & -.07 \\
\hline
\end{tabular}

\section{DISCUSSION}

This study aimed to identify how cognitive failures were related to mindfulness and separately to personality attributes. No earlier studies known to the authors had examined this area.

The study showed that there is a significant negative relationship between cognitive failures and mindfulness, indicating that the higher the mindfulness scores the lower the cognitive failure scores. This result supported the research by Carriere and others [2] which modeled a link between mindfulness and attention related cognitive failures and by Mrazek, Smallwood, and Schooler [52] which demonstrated a negative correlation between MAAS scores and mind-wandering (and that mindfulness exercises reduced mind-wandering). It seems that the emphasis in the literature on the value of mindfulness training and interventions would be supported by the results of our study, as increased mindfulness skills and responses are associated with decreased errors. This assumes that mindfulness is at least partly a state-based, developable skill and not simply a trait that is less open to change.

Hypothesis 2 examined personality factors in relation to cognitive failures. The results indicated that Neuroticism and Extraversion were both correlated with cognitive failures, positively for Neuroticism and negatively for Extraversion. These results are completely consistent (in relation to $\mathrm{N}$ ) and somewhat consistent in relation to extraversion with previous research [42]. The results were more neutral in regards to conscientiousness, agreeableness and openness than was anticipated from the meta-analytic reviews - though these had admittedly demonstrated somewhat inconsistent findings. .

Hypothesis 3 explored personality and its link with mindfulness, the study showing that mindfulness, for this employee group, was significantly negatively correlated with one of the Big Five factors, that is, neuroticism. There was no significant correlation between mindfulness and the other Big Five factors of agreeableness, conscientiousness, extraversion, and openness to experience, except for a significant negative correlation between extraversion and one only of the cognitive failures facets- 'blunders' at work.

\section{A. Implications of mindfulness in practice}

The benefits of mindfulness begin to be apparent when we realise how this state of mind is incompatible with neuroticism and cognitive failures. This leads to a consideration of whether - and how - mindfulness can be increased.

Mindfulness is a skill which can be learned as demonstrated in the many training or development programs available and by Langer herself in the early studies [10]. The recognition that mindfulness can be developed suggests that as individuals become more attentive to the conscious experience of their environment and more fully aware of the moment to moment experience, they will also develop higher levels of self awareness in context- and thus execute more positive actions with fewer cognitive errors. will

Langer [10] identified that individuals can increase mindfulness by: (1) reconceptualising the current situation and the context of this situation by making new categories in a mindful attentive way; (2) being receptive to new information in the environment by watching and listening, expanding awareness and information bases; and (3) being receptive also to information from others, becoming open to other perspectives and concentrating on whether our interactions with others have the desired effect. Improvement in awareness skills in each of these aspects is fundamental to many of the mindfulness training programs available. Given the strong correlations found between mindfulness and cognitive failures at work (leading to accidents and inefficiencies), mindfulness training would seem to have much to contribute in reducing the impacts of errors in the workplace.

\section{B. Methodological Issues and Limitations}

There were several potential limitations of the current study. First, all of the measures used were self-report and as such were limited by the reliability of that method and subject to error. Secondly, the sample size was relatively small and may have restricted the findings- though a reasonable cross-section of 92 workplace individuals participated. Participants were recruited mainly through their organisation and agreed to take part in the survey; it is not known if any workplace pressures might have influenced results or if non-volunteers would react differently from those who volunteered.

Thirdly, we used a single-domain measure of mindfulness to give an overall mindfulness score. Though this questionnaire, the MAAS, has been used extensively in research, there is a trend now to see mindfulness more in terms of specific aspects such as awareness and, separately, absent-mindedness [15], or as a sum of facets or multiple domains [48]. Nevertheless, our aim in using the MAAS was to identify how the general aspect of mindfulness related to cognitive failures and to global personality factors (the Big Five). We achieved our objective we believe, though more research should follow using broader definitions of mindfulness.

Fourthly, the CFQ is well-known and this first study (examining cognitive failures and the links to mindfulness and personality), has been able to present new information. However, cognitive failures could also be examined more contextually than through the CFQ which emphasises general characteristics across many contexts. 
Questionnaiures that target specific contexts could provide additional detailed information (for example, the workspecific measure of cognitive failures developed by Wallace and Chen [51]). There is more research to come but a gap in the literature has been addressed through the findings presented here.

\section{CONCLUSION}

Cognitive failures were found to be strongly related to neuroticism as a personality factor, and also to be strongly (negatively) related to mindfulness. The importance of these findings cannot easily be understated as mindfulness is a state-like, trainable, improvable characteristic. If individuals can be less focused on their internal environment and less susceptible to lapses of attention, and if training and experience can develop mindfulness further, then there are likely to be many benefits in organisational life including in occupational health and safety. The results from the current study suggest there could be spin-offs in fewer personal and workplace errors from higher levels of mindfulness exhibited in the workplace. Future research should examine outcomes of mindfulness training in different occupational settings. Certainly any research that can contribute to decreased errors at work and improved work performance generally would be worth attention. Not only does mindful awareness seem to have many benefits personally, spiritually, and in health; it seems that improved mindfulness can help reduce our large costs from cognitive failures at work.

\section{REFERENCES}

[1] M. Martin, "Cognitive failure: Everyday and laboratory performance," Bulletin of Psychonomic Society, vol. 21, pp. 97-100, 1983.

[2] J. Carriere, J.A. Cheyne, and D. Smilek, "Everyday attention lapses and memory failures: The affective consequences of mindlessness," Consciousness and Cognition, vol. 17, pp. 835-847, 2008.

[3] J. Smallwood, J.B. Davies, D. Heim, F. Finnigan, M. Sudberry, R. O'Connor, and M. Obonsawin, "Subjective experience and the attention lapse: Task engagement and disengagement during sustained attention," Consciousness and Cognition, vol. 13, pp. 657-690, 2004.

[4] S.J. Kass, S.J. Vodanovich, C. Stanny, and T. Taylor, "Watching the clock: Boredom and vigilance performance," Perceptual and Motor Skills, vol. 92, pp. 969-976, 2001.

[5] C.J. Wallace, S.J. Kass, and C.J. Stanny, "The cognitive failures questionnaire revisited: Dimensions and correlates," The Journal of General Psychology, vol. 129, pp. 238-256, 2002.

[6] E. Dane, and B.J. Brummel, "Examining workplace mindfulness and its relations to job performance and turnover intention," Human Relations, vol. 67, pp. 105-128, 2014.

[7] K. Brown, and R. Ryan, "The benefits of being present: Mindfulness and its role in psychological well-being," Journal of Personality and Social Psychology, vol. 84, pp. 822-848, 2013.

[8] G. Claxton, "Mindfulness, learning and the brain," Journal of Rational-Emotive and Cognitive-Behavior Therapy, vol. 23, pp. 301314, 2005.

[9] J. Kabat-Zinn, "Mindfulness meditation: What it is, what it isn't, and its role in health care and medicine," In Y. Haruki, Y. Ishii, \& M. Suzuki (Eds.), Comparative and psychological study on meditation. Delft: Eburon, 1996.
[10] E.J. Langer, "Mindfulness," Addison-Wesley Publishing Co, Inc, 1989.

[11] B. Khoury, T. Lecomte, G. Fortin, M. Masse, P. Therien, V. Bouchard, M. Chapleau, K. Paquin, and S.G. Hofmann, "Mindfulnessbased therapy: A comprehensive meta-analysis," Clinical Psychology Review vol. 33, pp. 763-771, 2013.

[12] E. Shonin, W. Van Gordon, and M.D. Griffiths, "Mindfulness-based interventions: Towards mindful clinical integration," Frontiers of Psychology, vol. 4, pp. 194, 2013.

[13] A.S. Troy, A.J. Shallcross, T. Davis, and I.B. Mauss, "History of mindfulness-based cognitive therapy is associated with increased cognitive reappraisal ability. Mindfulness. Advance online publication, 2012.

[14] D. Birrer, P. Röthlin, and G. Morgan, "Mindfulness to enhance athletic performance: Theoretical considerations and possible impact mechanisms,“"Mindfulness, vol. 3, pp. 235-246, 2012.

[15] J. Reb, J. Narayanan, and Z.W. Ho, "Mindfulness at work: Antecedents and consequences of employee awareness and absentmindedness," Mindfulness. Research Collection Lee Kong Chian School of Business, 2013

[16] M. Elliot, "Being mindful about mindfulness: An invitation to extend occupational engagement into the growing mindfulness discourse," Journal of Occupational Science, vol. 18, pp. 366-376, 2011.

[17] J. Reason, J. "The Human Contribution: Unsafe acts, accidents and heroic recoveries," Ashgate, Aldershot, 2009.

[18] E.J. Langer, and M. Moldoveanu, M, "The construct of mindfulness," Journal of Social Issues, vol. 56, pp. 1-9, 2000.

[19] R. Baer, "Measuring mindfulness," Contemporary Buddhism: An Interdisciplinary Journal, vol. 12, pp. 241-261, 2011.

[20] M. Batchelor, "Meditation and mindfulness," Contemporary Buddhism, vol. 12, pp. 157-164, 2011.

[21] M. Cullen, "Mindfulness-based interventions: An emerging phenomenon," Mindfulness, vol. 2, pp. 186-193, 2011.

[22] J. Dunne, "Towards an understanding of non-dual mindfulness," Contemporary Buddhism, vol. 12, pp. 71-88, 2011.

[23] E. Maex, "The Buddhist roots of mindfulness training: A practitioners view," Contemporary Buddhism, vol. 12, pp. 165-175, 2011.

[24] P. Sedlmeier, J. Eberth, M. Schwarz, D. Zimmermann, F. Haarig, S Jaeger, and S. Kunze, S. "The psychological effects of meditation: A meta-analysis," Psychological Bulletin, May 14, No Pagination Specified, 2012.

[25] J.D. Teasdale, and M. Chaskalson, "How does mindfulness transform suffering: The transformation of dukkha," Contemporary Buddhism. vol. 12, pp. 89-92, 2011.

[26] J.M.G. Williams, and J. Kabat-Zinn, "Mindfulness: Diverse perspectives on its meaning, origins, and multiple applications at the intersection of science and dharma," Contemporary Buddhism, vol. 12, pp. 1-18, 2011.

[27] R. Baer, R, "Mindfulness training as a clinical intervention: a conceptual and empirical review," Clinical Psychology Science \& Practice vol. 10, pp. 125-143, 2003.

[28] E. Dane, "Paying attention to mindfulness and the effects on task performance in the workplace," Journal of Management, vol. 37, 1-22, 2010.

[29] R.W. Thompson, K.A. Kaufman, L.A. De Petrillo, C.R. Glass, and D.B. Arnkoff, "One year follow-up of mindful sport performance enhancement (MSPE) with archers, golfers, and runners," Journal of Clinical Sport Psychology, vol. 5, pp. 99-116, 2011.

[30] A. Di Fabio, "Decisional procrastination correlates: Personality traits, self-esteem or perception of cognitive failure?" International Journal of Educational Vocational Guidance, vol. 6, pp. 109-122. 2006. 
[31] R. McCrae, and P. Costa, "Personality trait structures as human universal," American Psychologist, vol. 52, pp. 509-516, 1997.

[32] J.W. Hart, M.F. Stasson, J.M. Mahoney, and P. Story, "The Big Five and achievement motivation: Exploring the relationship between personality and a two-factor model of motivation," Individual Differences Research, vol. 5, pp. 267-274, 2007.

[33] S. Clarke, and I. Robertson, "A meta-analytic review of the Big Five personality factors and accident involvement in occupational and nonoccupational Settings," Journal of Occupational and Organizational Psychology, vol. 78, pp. 355-376, 2005.

[34] F.K. Lee, K.M. Sheldon, \& D.B. Turban, "Personality and the goalstriving process: The influence of achievement goal patterns, goal level, and mental focus on performance and achievement," Journal of Applied Psychology, vol. 88, pp. 256-265, 2003.

[35] K. Klockner, and R.E. Hicks, "My next client: Understanding the big five and positive personality dispositions of those seeking psychosocial support interventions," International Journal of Coaching Psychology, vol. 3, pp. 148-153, 2008.

[36] D. Zweig, and J. Webster, "What are we measuring? An examination of the relationships between the Big-Five personality traits, goal orientation and performance intentions," Personality and Individual Differences, vol. 36, pp. 1693-1708, 2004.

[37] S. Clarke, "Contrasting perceptual, attitudinal and dispositional approaches to accident involvement in the workplace," Safety Science, vol. 44, pp. 537-550, 2006.

[38] J. Salgado, "The Big Five personality dimensions and counterproductive behaviours," International Journal of Selection and Assessment, vol. 10, pp. 117-25, 2002.

[39] C. Tomlinson-Keasy, and T.D. Little, "Predicting educational attainment, occupational achievement, intellectual skill, and personal adjustment among gifted men and women," Journal of Educational Psychology, vol. 82, pp. 442-455, 1990.

[40] J.J. Walsh, M.G. Balint, D.R. Smolira, L.K. Fredericksen, \& S Madsen, "Predicting individual differences in mindfulness: The role of trait anxiety, attachment anxiety and attentional control," Personality and Individual Differences, vol. 46,pp. 94-99, 2009.

[41] C.L.M. Hill, and JA. Updegraff, "Mindfulness and its relationship to emotional regulation," Emotion, vol. 12, pp. 81-90, 2012.

[42] T. Giluk, "Mindfulness, Big Five personality, and affect: A metaanalysis," Personality and Individual Differences, vol. 47, pp. 805811, 2009.

[43] S.G. Hofmann, A.T. Sawyer, A.A. Witt, and D. Oh, "The effect of mindfulness-based therapy on anxiety and depression: A meta-analytic review," Journal of Consulting and Clinical Psychology, vol. 78, pp 169-183, 2010 .

[44] K. Klockner, "Keeping my mind on the job: Mindfulness and Workplace Safety," Paper presented at First International Conference on Mindfulness, Rome, Italy (2013, May 8-12).

[45] K. Klockner, and R. Hicks, "Individual Mindfulness, Cognitive Failures and Personality (the Big Five) in a Workplace Sample", Paper presented at First International Conference on Mindfulness, Rome, Italy (2013, May 8-12)

[46] K. Klockner, and R. Hicks, "Workplace errors, mindfulness and personality: Relating cognitive failures at work to Mindfulness and to the Big Five factors," Paper presented at the $41^{\text {st }}$ conference of the Academy of International Business (United Kingdom and Ireland) (AIB-UKI), held University of York, United Kingdom (2014, April 10-12).

[47] D. Broadbent, P. Cooper, P. Fitzgerald, and K. Parkes, "The Cognitive Failures Questionnaire (CFQ) and its correlates," British Journal of Clinical Psychology, vol. 21, pp. 1-16, 1982.
[48] C. Bergomi, W, Tschacher, K. Zeno, "The assessment of mindfulness with self-report measures: Existing scales and open issues," Mindfulness, vol. 4, pp. 191-202, 2013.

[49] P. Grossman, "Defining mindfulness by how poorly I think I pay attention during everyday awareness and other intractable problems for psychology's (re)invention of mindfulness: Comment on Brown et al.," Psychological Assessment, vol. 23, pp. 1034-1040, 2011.

[50] L.R. Goldberg, J.A. Johnson, H.W. Eber, R. Hogan, M.C. Ashton, C.R. Cloninger, and H.C. Gough, "The International Personality Item Pool and the future of public-domain personality measures," Journal of Research in Personality, vol. 40, pp. 84-96, 2006.

[51] C.J. Wallace, and G. Chen, "Development and validation of a work specific measure of cognitive failure: Implications for occupational safety," Journal of Organisational and Occupational Psychology," vol. 78, pp. 615-632, 2005.

[52] M.D. Mrazek, J. Smallwood, and J.W. Schooler, "Mindfulness and mind-wandering: Finding convergence through opposing constructs," Emotion. Advance online publication, 2012

\section{AUTHORS’ PROFILE}

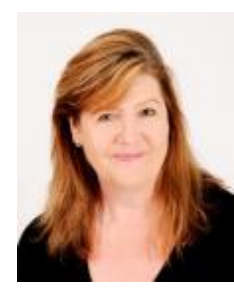

Karen Klockner is Senior Lecturer at Central Queensland University (CQU) in the School of Human, Health and Social Services teaching into the OH\&S, Human Factors, Rail Safety and Accident Phenomenology programs. Prior to her CQU appointment Karen held several applied psychology and management positions including Manager of Human Factors, Rail Safety Regulation Branch, in the Queensland Department of Transport and Main Roads. Karen is a Registered Psychologist, holds a Masters in Human Factors \& Safety Management Systems; and is currently completing a $\mathrm{PhD}$ in Acciden Modelling for the Rail Industry; she has strong interests also in mindfulness in the workplace.

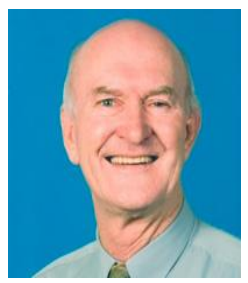

Dr Richard E Hicks is Professor of Psychology at Bond University with research interests in occupational, clinical and counseling psychology. His academic and professional background includes appointments in Australia, Africa (in Zambia) and Papua New Guinea, and sabbaticals in the UK and the USA. He has special interests in personality and its applications in the workplace. 